\title{
WEEE management in a circular economy perspective: an overview
}

\author{
Cesaro A. ${ }^{1,}{ }^{*}$, Marra A. ${ }^{1}$, Kuchta K. ${ }^{2}$, Belgıorno V. ${ }^{1}$ and Van Hullebusch E.D. ${ }^{3,4}$ \\ ${ }^{1}$ SEED - Department of Civil Engineering, University of Salerno, via Giovanni Paolo II, 84084 Fisciano (SA), Italy \\ 2IUE - Technische Universität Hamburg, Harburger Schloßstr. 36, 21079 Hamburg, Germany \\ 3Department of Environmental Engineering and Water Technology, IHE Delft Institute for Water Education, Westvest 7, AX Delft 2611, \\ the Netherlands \\ 4 Laboratoire Géomatériaux et Environnement (EA 4508), UPEM, Université Paris-Est, Marne la Vallée 77454, France \\ Received: 12/02/2018, Accepted: 09/11/2018, Available online: 21/11/2018 \\ *to whom all correspondence should be addressed: e-mail: acesaro@unisa.it \\ https://doi.org/10.30955/gnj.002623
}

\begin{abstract}
The circular economy approach represents a strategy to optimize product lifecycles, thus improving the sustainability of consumption patterns. In the European Union a recent legislative proposal has addressed this concept by promoting waste prevention and re-use as well as extensive recovery of materials. Such approach is particularly interesting for the management of Waste Electrical and Electronic Equipment (WEEE), that is regarded as an urban stock of different metals, and in particular of both precious metals and rare earth elements. The recovery of metals is the main focus of WEEE management strategies and, more recently, it has been receiving a great deal of attention, especially due to the continuously increasing production of this waste stream. However, great room for improvements can still be recognised to ensure the overall sustainability of WEEE management. The present work discusses both the current needs and the main challenges regarding WEEE management in a circular economy perspective. To this end, WEEE generation trend and composition is provided and the legislative framework for its handling is overviewed, in order to point out future perspectives to develop a more sustainable management approach of this waste.
\end{abstract}

Keywords: Precious metals, rare earth elements, recovery, recycling, sustainability, waste electrical and electronic equipment.

\section{Introduction}

The production of waste has been traditionally regarded as a wealth indicator: the better is the economic condition of a community, the greatest is its tendency to consume and, as a consequence, to generate residues. The recognition of such a relationship addressed the introduction of strategies, aiming at decoupling the economic growth from the increase in waste production, which have been recently brought into the concept of "circular economy". It is a completely new approach in the field of waste management, which goes beyond prevention and recycling, changing the function of resources in the economy. The actions following the circular economy approach aim at the minimization of waste production through eco-design, the development of new business models as well as the identification of new recycling technologies to return raw materials back to production processes.

In this view, the management of Waste Electrical and Electronic Equipment (WEEE) is particularly challenging.

WEEE is the kind of waste characterized by the highest growth rate per year (Cucchiella et al., 2015; Tuncuk et al., 2012): in 2014 approximately 41.8 million tons of WEEE were estimated to be globally generated (Baldé et al., 2015) and around 65.4 million tons were predicted in 2017 (UNEP, 2013). Moreover, it has a complex composition, including relatively high concentrations of base and precious metals (Lee and Pandey, 2012; Tuncuk et al., 2012) as well as the presence of rare earth elements (REEs) which are classified as critical raw materials with high industrial interest (Cossu and Williams, 2015).

In the transition towards a circular economy approach, the recycling of WEEE is, thus, a relevant opportunity in both environmental and economic terms (Cui and Zhang, 2008). To this end, the development of both innovative recycling technologies and new business models to process complex materials from WEEE stream in more energy efficient and environmental friendly manner is essential (Tesfaye et al., 2017).

This paper aims at overviewing the key points of WEEE management under a circular approach.

As a comprehensive understanding of the characteristics of the material to be processed is essential in order to set a sustainable handling strategy (Chancerel and Rotter, 2009; Cui and Forssberg, 2003), the elemental composition of WEEE is presented with a focus on the contents of both base and strategic metals, as the precious ones and rare earth elements. Moreover, bearing in mind that the management of waste designed for material recovery is addressed by legislation and promoted by clearly identified 
economic drivers boosting the business, the legislative framework for WEEE management in the European Union as well as in other countries is outlined. The discussion is addressed towards the identification of the current needs and the main challenges for the sustainable management of WEEE in a circular economy perspective.

\section{WEEE generation and composition}

\subsection{Production trends}

The quantification of WEEE flows is a fundamental prerequisite to develop effective and sustainable management solutions. However, the global monitoring of such waste streams is challenged by lack of reliable data. The difficulty of mapping WEEE flows is related to several factors, including: (i) the collection outside official take-back systems in developed countries; (ii) the transboundary movement of electronic waste mostly from developed to developing countries; (iii) the informal collection systems in developing countries.

Moreover, the different lifespan of electronic devices within the several categories and the typical accumulation of obsolete small equipment in households contribute to hinder WEEE quantification (Baldé et al., 2015; Bigum et al., 2012).

Figure 1 displays the amount of domestic WEEE produced in 2014 by European (a.) and non-European countries (b.).

Although the specific production varies considerably among different States, WEEE generation is directly related with the population wealth, so that in Denmark, Sweden, France, Austria, Germany, Belgium, Norway and Switzerland the WEEE pro-capita production reaches values above $20 \mathrm{~kg}$ per inhabitant while in countries as India, Philippines and Africa it remains rather low.

When considering the overall production, in 2014 the United States of America (USA) were the major WEEE producer with 7072 kilo tons of electronic waste generated. China follows the top of the ranking, generating 6033 kilo tons of WEEE; Japan and India were just behind with a production of 2200 and 1641 kilo tons, respectively. In the same year, approximately $6 \mathrm{~kg}$ of WEEE per capita were globally generated, but only the $15.5 \%$ has been reported to be formally treated (Baldé et al., 2015).

\subsection{The content of metals}

The wide number of electric and electronic appliances, the year of production, the origin as well as the manufacturer make WEEE material composition highly variable and difficult to generalize. However, metals cover the dominant material fraction accounting for approximately $60 \%$ by weigh (Tuncuk et al., 2012; Widmer et al., 2005).

The metal fraction is composed by a variety of base metals, including aluminium (Al), copper (Cu), iron (Fe), lead (Pb), nickel ( $\mathrm{Ni})$, tin $(\mathrm{Sn})$ and zinc $(\mathrm{Zn})$, which are mainly present in printed circuit boards (PCBs). When considering the entire WEEE rather than its components, few information is available. a.

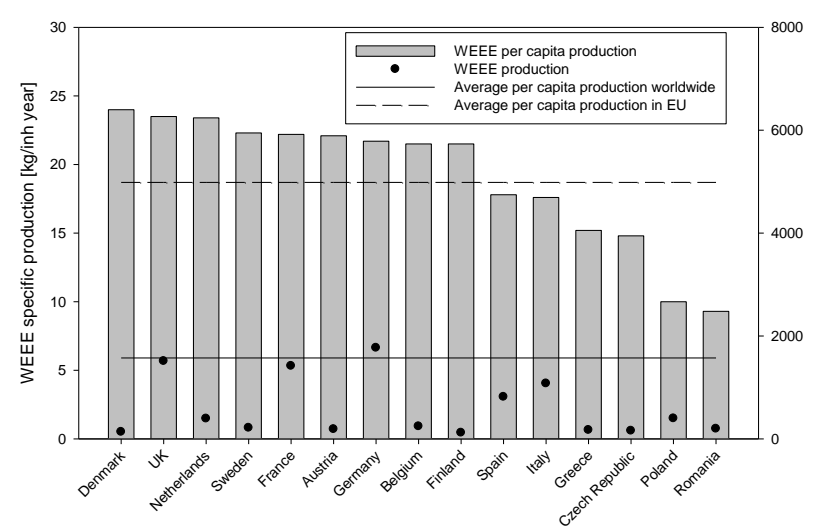

b.

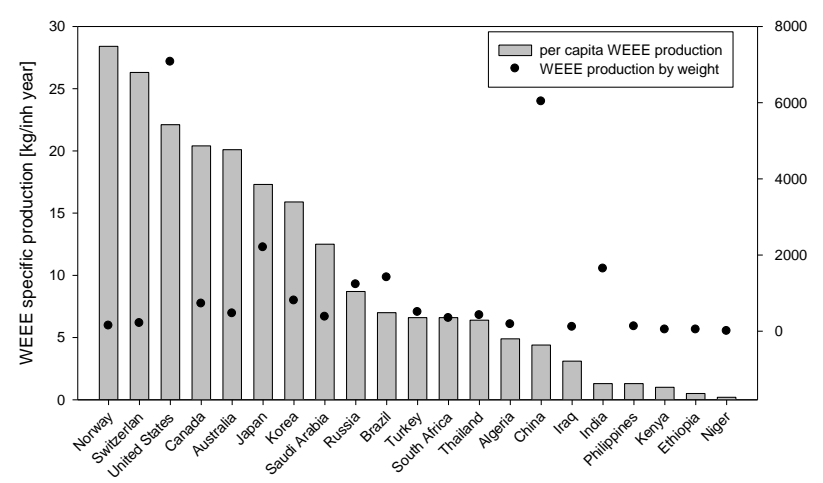

Figure 1. WEEE generated in 2014 in EU (a.) and non EU (b.) countries (www.step-initiative.org)

Morf et al. (2007) detected around $49000 \mathrm{mg} / \mathrm{kg}$ of $\mathrm{Al}$, $41000 \mathrm{mg} / \mathrm{kg}$ of $\mathrm{Cu}, 360000 \mathrm{mg} / \mathrm{kg}$ of Fe, $10300 \mathrm{mg} / \mathrm{kg}$ of $\mathrm{Ni}, 2900 \mathrm{mg} / \mathrm{kg}$ of $\mathrm{Pb}, 1700 \mathrm{mg} / \mathrm{kg}$ of $\mathrm{Sb}$ and $5100 \mathrm{mg} / \mathrm{kg}$ of $\mathrm{Zn}$ in small WEEE, including consumer electronics (audio, video) as well as IT and telecommunication equipment, entering a recycling plant in Switzerland. In roughly agreement with these values, Oguchi et al. (2012) found Fe $(480000 \mathrm{mg} / \mathrm{kg})$ as the most prevalent metal in input WEEE at a Japanese municipal waste treatment plant, treating both large and small household appliances, information technology and communications equipment, consumer and lighting equipment. They found a content of $\mathrm{Cu}$ and $\mathrm{Al}$ with one order of magnitude lower than iron whereas $\mathrm{Pb}, \mathrm{Sn}$ and $\mathrm{Zn}$ were on the order of $10^{3}$ $\mathrm{mg} / \mathrm{kg}$. However, it should be pointed out that different proportions of items in input WEEE determine different metal content.

Moreover, WEEE contains less common metals, as bismuth (Bi), cobalt ( $\mathrm{Co})$, gallium ( $\mathrm{Ga})$, strontium $(\mathrm{Sr}$ ) and tantalum (Ta), as well as others defined as toxic metals, including barium (Ba), beryllium (Be), cadmium ( $\mathrm{Cd}$ ), chromium ( $\mathrm{Cr}$ ), lead $(\mathrm{Pb})$ and antimony $(\mathrm{Sb})$, which raise great concern and set the need for an appropriate management of this waste stream (Oguchi et al., 2011, 2013). 
Among base metals, copper and zinc are those with the higher economic value (Cui and Zhang, 2008) as well as the more relevant concentrations. Conventional WEEE treatment processes are thus directed to the selection and recovery of this kind of metals. Copper generally makes of around $10-20 \%$ of the PCB total weight; $4-6 \%$ consists of $\mathrm{Pb} / \mathrm{Sn}$ solders while the remaining metallic fraction is composed of other metals, including the precious ones (Ghosh et al., 2015).

Gold $(\mathrm{Au})$, silver $(\mathrm{Ag})$ and platinum-group metals (PGMs), including platinum $(\mathrm{Pt})$, palladium $(\mathrm{Pd})$, rhodium $(\mathrm{Rh})$, ruthenium ( $\mathrm{Ru})$, iridium (Ir) and osmium (Os), are mainly present in PCBs (Table 1), either connected or mixed with other metals in contacts, cables, solders and hard disk drives or with ceramics in multi-layer capacitors, integrated circuits and hybrid ceramics or, furthermore, with plastics in PCB-tracks, inter-board layers and integrated circuits (Hagelüken, 2006). However PCBs represent only 3-6\% of the WEEE mass (Cucchiella et al., 2015).

Differently from base metals, the concentration of the precious ones in WEEE is rather low. However, their economic relevance is very high. Moreover, the concentration of precious metals in PCBs is generally much higher than that in mineral ores and the environmental impacts associated with the production from secondary sources is much lower than their primary production. For instance, Chancerel (2010) reported that approximately 540 tonnes of virgin material have to be used in order to produce just one gram of gold.

Table 1. Precious metal content in selected WEEE

\begin{tabular}{|c|c|c|c|c|c|}
\hline \multirow{2}{*}{ Equipment type } & \multicolumn{4}{|c|}{ Precious metal concentrations (mg/kg) } & \multirow{2}{*}{ Ref. } \\
\hline & $\mathbf{A g}$ & $\mathrm{Au}$ & Pd & $\mathbf{P t}$ & \\
\hline LCD notebooks & 71 & 63 & 11 & 1 & Cucchiella et al., 2015 \\
\hline LED Notebooks & 71 & 63 & 11 & 1 & Cucchiella et al., 2015 \\
\hline LCD TVs & 45 & 11 & 4 & - & Cucchiella et al., 2015 \\
\hline LED TVs & 45 & 11 & 4 & - & Cucchiella et al., 2015 \\
\hline CRT Monitors & 78 & 19 & - & - & Cucchiella et al., 2015 \\
\hline LCD Monitors & 104 & 40 & 8 & - & Cucchiella et al., 2015 \\
\hline LED Monitors & 104 & 40 & 8 & - & Cucchiella et al., 2015 \\
\hline \multirow[t]{2}{*}{ Cell Phones } & 12500 & 300 & 113 & - & Cucchiella et al., 2015 \\
\hline & 1340 & 350 & 210 & - & Hagelüken, 2006 \\
\hline Smart Phones & 2033 & 317 & 125 & 33 & Cucchiella et al., 2015 \\
\hline HDDs & 53 & 9 & 5 & - & Cucchiella et al., 2015 \\
\hline SSDs & 78 & 13 & 8 & - & Cucchiella et al., 2015 \\
\hline Tablets & 100 & 88 & 16 & - & Cucchiella et al., 2015 \\
\hline Portable audio & 150 & 10 & 40 & - & Hagelüken, 2006 \\
\hline DVD player & 115 & 15 & 4 & - & Hagelüken, 2006 \\
\hline Calculator & 260 & 50 & 5 & - & Hagelüken, 2006 \\
\hline
\end{tabular}

Table 2 Content of REEs in selected WEEE (Cucchiella et al., 2015)

\begin{tabular}{|c|c|c|c|c|c|c|c|c|c|}
\hline \multirow{2}{*}{ Equipment type } & \multicolumn{9}{|c|}{ REE concentrations (mg/kg) } \\
\hline & $\mathrm{Ce}$ & Dy & Eu & Gd & La & Nd & $\operatorname{Pr}$ & $\mathbf{T b}$ & $Y$ \\
\hline LCD notebooks & $<0.3$ & 17 & $<0.3$ & $<0.3$ & $<0.3$ & 600 & 78 & $<0.3$ & 0.6 \\
\hline LED Notebooks & $<0.3$ & 17 & $<0.3$ & $<0.3$ & - & 600 & 78 & - & 0.6 \\
\hline LCD TVs & 0.5 & - & 0.8 & $<0.1$ & 0.7 & - & $<0.1$ & 0.2 & 11 \\
\hline LED TVs & $<0.1$ & - & $<0.1$ & 0.2 & - & - & - & - & 0.5 \\
\hline CRT Monitors & - & - & - & - & - & - & - & - & 62 \\
\hline LCD Monitors & $<0.2$ & - & 0.2 & $<0.2$ & $<0.2$ & - & $<0.2$ & $<0.2$ & 3.2 \\
\hline LED Monitors & $<0.2$ & - & $<0.2$ & 0.4 & - & - & - & - & $<0.2$ \\
\hline Smart Phones & - & - & - & - & - & 417 & 83 & - & - \\
\hline HDDs & - & 103 & - & - & - & 1724 & 250 & - & - \\
\hline Tablets & $<2$ & 24 & $<2$ & $<2$ & $<2$ & 854 & 110 & $<2$ & $<2$ \\
\hline
\end{tabular}

WEEE is considered as an interesting "urban mining" target not only for precious metals, but also for REEs. These are a group of 17 metallic elements, including 15 lanthanides, namely lanthanum (La), cerium (Ce), praseodymium ( $\mathrm{Pr}$ ), neodymium $(\mathrm{Nd})$, promethium $(\mathrm{Pm})$, samarium $(\mathrm{Sm})$, europium (Eu), gadolinium (Gd), terbium (Tb), dysprosium (Dy), holmium (Ho), erbium (Er), thulium (Tm), ytterbium $(\mathrm{Yb})$, and lutetium (Lu) plus scandium (Sc) and yttrium (Y).
REEs can be found in cathode ray tube (CRT), fluorescent lamps, magnets, accumulators, electrodes, semiconductors, capacitors and electric contacts (Menad and van Houwelingen, 2011).

As some of them have been recently claimed as critical raw materials for the economy of the European Union, the interest towards their recycling has been growing exponentially. However, the research on REE recycling has 
been mainly focused on three categories of end-of-life products: those containing phosphors which are capable of luminescence; devices containing permanent magnets and batteries due to their REE contents (Tunsu et al., 2015).

A relevant obstacle in proposing recycling technologies for REEs is in the fragmentation of data on their concentrations in WEEE, which is tightly related to trade secrets which cover some devices (Buchert et al., 2012).

A characterization in terms of critical materials of selected WEEE has been provided by Cucchiella et al. (2015): the data reported in Table 2 show that the concentration of REEs in WEEE is very low, especially when compared with base metals. This aspect could further hinder the implementation of proper recovery technology at industrial scale.

\section{The legislative framework for WEEE management}

In many countries worldwide, WEEE management is formally disciplined by specific Regulations. The strategies enforced by law usually adopt the extended producer responsibility (EPR) as the key aspect for the management of this kind of waste (Tanskanen, 2013).

South Africa, Kenya and Nigeria are the only African countries that have recently implemented the EPR strategy (Li et al., 2013). However, in Africa informal sector still plays a significant role in WEEE processing (Ongondo et al., 2011). Moreover, $88 \%$ of African destinations countries involved in the transboundary movements of electronic waste have not yet established regulation on WEEE import (Li et al., 2013).

In Asia, China, Malaysia, India, Hong-Kong, Japan and South Korea have enforced EPR regulations. Although some of these countries banned the import of WEEE, in others the illegal traffic is still prevalent. In Japan the illegal dump of WEEE as well as the intensive end-of-life export as secondhand goods are likely stimulated by the recycling fees (Ongondo et al., 2011).

The illegal WEEE management affects also European countries, where only one-third of this waste is reported to be separately collected and treated (www.ec.europa.eu) in accordance with the WEEE Directive.

\subsection{The European WEEE directive}

In the European Union, the management of WEEE is disciplined by the WEEE Directive 2012/19/EU, which entered into force on the $13^{\text {th }}$ of August 2012, being effective since the $14^{\text {th }}$ of February 2014.

The electrical and electronic equipment (EEE) including appliances powered by electric currents or electromagnetic fields as well as equipment for the generation, transfer or measurement of such currents and fields, which the holder discards or intends or is required to discard fall under the WEEE Directive.

The Directive on the restriction of the use of certain hazardous substances in EEE or RoHS (Restriction of Hazardous Substances) Directive represents a further reference, setting the beginning-of-pipe of EEE lifecycle (Schluep, 2014).
In accordance with the EPR principle, the WEEE Directive put on EEE producers the responsibility, physical and/or economic, for the take back and the recycling of their postconsumer products. Such responsibility aims at promoting the development of sustainable design of electric and electronic products, namely eco-design, in order to simplify reuse or recycle. The implementation of eco-design for EEE would indeed promote recycling and result in the reduction of the waste management costs that are assigned to producers. According to the Directive, producers can address their duties individually or creating producer responsibility organizations (PROs), thus setting up either individual or collective take-back systems.

However, for developing an efficient and sustainable management system, not only producers but all the stakeholders and the operators, from governments to consumers as well as recycling industry, need to be involved (Tanskanen, 2013). In this view, it is worth pointing out that the European WEEE Directive introduced also a responsibility for distributors, namely any natural or legal person who makes an electric or electronic device available on the market. Distributors have to ensure that the obsolete EEE can be returned at least free of charge on a one-to-one basis when a new equal equipment is supplied. The role of consumers has been outlined as well, as they have to actively contribute to the successful collection of WEEE.

This formally identified systems is adopted to ensure environmental prevention, by promoting WEEE separate collection and recovery. To this end, the WEEE Directive fixed collection targets for all WEEE, based on volumes of the corresponding EEE placed on the market: $65 \%$ of the average weight of EEE placed on market in the previous three years has to be collected by 2019.

Recovery targets were set as well, in order to ensure that WEEE collected is then properly treated.

\section{Needs and challenges for WEEE handling under a circular approach}

The globally increasing trend in WEEE production and its heterogeneous composition, which makes this waste both a potential source of secondary materials and a vehicle of hazardous substances if improperly handled, require the implementation of sustainable management strategies (Rubin et al., 2014).

The currently established legislative frameworks, when existing, implement the principle of the Extended Producer Responsibility, with the main aim of reducing adverse health and environmental effects from WEEE unregulated practices. However, such approach is still far away from promoting the management of this waste stream in a circular perspective, so that specific challenges can be identified to fulfill the current needs.

\subsection{WEEE characterization}

The material composition of WEEE acquire fundamental importance to set up proper management strategies.

This category of waste includes a wide range of electric and electronic appliances, constantly evolving in accordance 
with the product technological innovation, so that it is difficult to create a harmonized list of end-of-life electric and electronic appliances.

The literature review highlighted that scattered information is available, especially if referred to REEs: the trade secret covering some devices is a relevant obstacle in the collection of reliable data about the concentration of the different materials composing a specific equipment.

Most scientific works report the characterization of WEEE components, mainly in terms of metals. However, the relevance of these data is limited as usually few details (origin, manufacturer, year of production, ...) about the analyzed component are given. Moreover, the lack of standard methods to assess total element concentration in WEEE results in the application of different protocols which, in turn, affects the outcome of the analytical determination as well as the comparability of data from different experimental works.

The creation of an official database including data on WEEE components and their material composition represents a challenging as well as pressing issue, that should be addressed together with the identification of shared and scientifically-based standard analytical procedures to optimize the characterization of methods and to ensure the comparability of results.

\subsection{Collection programs and take back and strategies}

In order for WEEE to enter the formal handling system, it has to be taken back and this requires both supporting policies and proper infrastructures. In this view, different priorities can be recognized in different global regions.

In countries (e.g. European Member States, USA, India, Canada, ...) where specific legislations are enforced, collection is formally identified and differently implemented in accordance with the EPR principle. In these countries, the improvement of collection rates must be pursued. Corsini et al. (2017) recently pointed out the relevance of a more productive cooperation between the private and public sectors by implementing competitive collection systems. Moreover, in order to implement WEEE management in a circular perspective, collection methods should effectively promote recycling and, in this view, the design of systems ensuring the concentration of critical metals in source selected WEEE streams can be regarded as the main challenge.

Different needs can be recognized in the countries lacking in both specific legislation and WEEE handling capacity, which is expected to develop to a worse scenario due to the increasing WEEE amount. In these regions, the identification of effective policies represents a key challenge to be faced. Filling this gap is not an easy task and, although the existing experience can be addressed, the identification of the most sustainable strategies to intercept WEEE streams must take into account region-specific conditions.

It is worth pointing out that the absence of a legislative framework also contributes to the growth of the informal WEEE management sector. It is mostly fed by illegal e-waste trade, including both imported and domestic stockpiled WEEE, so that it represents a concern of both exporting and importing countries. Both banning WEEE import and improving formal collection rate could limit the volume of WEEE entering the informal sector and tracking the waste is thus fundamental. However, as spotted initiatives could prove to be ineffective, data from local monitoring systems should convey to a wider, internationally based network.

\subsection{Recycling processes}

The identification of innovative recycling technologies stands as a backbone of the circular economy approach.

At industrial scale, recycling processes currently include a pre-treatment stage, usually based on mechanical separation techniques, and a refining stage to get target materials. It is well known that pretreatments are designed to select base metals, so that they are responsible for great losses of critical metals, which tend to concentrate in output streams not destined to further recovery. Moreover, only few facilities hold the technical know-how to effectively implement the refining stage (Tansel, 2017). In this context, despite the economic value of the recoverable materials from WEEE, the recycling industry is not well developed, because the profitability does not properly counterbalance both capital and operating costs.

In the last decade, numerous studies have investigated alternative recycling treatments, but great room for improvement can be still identified. The efficiency of the proposed techniques is indeed negatively affected by the complexity of most WEEE components, which would require both expensive and labor-intensive pretreatments. WEEE complexity also accounts for the poor selectivity of refining processes.

WEEE recycling in a circular economy perspective should entail the maximization of resource extraction from waste, while pursuing the reduction of the related environmental impacts (Cesaro et al., 2017a). To this end, both the improvement of EEE recyclability and recycling process upgrade can play a key role and can be regarded as the main challenges in this field.

The utilization of hazardous substances in EEE should be more and more limited, so as to enhance the environmental compatibility of the subsequent recycling process (Guna et al., 2016; Cesaro et al., 2017b).

It is worth pointing out that some potentially hazardous substances have already been replaced in WEEE manufacturing processes, but both heavy metals and organic pollutants are still present (Baldé et al., 2015). As already discussed for the valuable fractions, the scarce information about WEEE characterization in terms of hazardous materials can represent an obstacle in setting up innovative recycling technologies that are intended to be also environmentally-friendly.

More recently, green electronic processes, referring to the pioneer use of bio-based electronic components, have also been proposed (Guna et al., 2016). Although this kind of technology can be regarded as an option to reduce the 
potential hazard associated to recycling practices, further efforts should be provided to ensure their scale up.

Electric an electronic goods should also be designed and realized in order to make their disassembly easier. Such condition would not only facilitate the pretreatment for recovery, but it would also positively affect the reuse and refurbishing of end-of-life appliances in accordance with the circular economy principle.

The sustainability of recycling processes should entail, together with the environmental compatibility, the profitability. The process has to end up in a material that can be effective used to replace natural resources, while lowering the environmental burdens. To this end, the pretreatment step should rely on more sophisticated automatic techniques, capable of dealing with WEEE material complexity. The more effectively the disassembly is performed, the higher will be the material recovery yields of the overall process.

As for the refining stage, the need to shift from conventional metal recovery processes based on pyro- and hydro-metallurgical techniques to more environmentally sound treatments has driven the research interest towards bio-metallurgical treatments (Isildar et al., 2017).

Although both bioleaching and biosorption processes have been proven to be promising techniques, the prolonged reaction time as well as the low loading capacity as solid materials to be treated still hinder their scale up.

\subsection{Human health and environmental protection}

The presence of hazardous substances in WEEE and their possible release into the environment raise great concern about the adverse effects on human health. These effects, which have been largely described in scientific literature (Sepúlveda et al., 2010; Tsydenova and Bengtsson, 2011), are particularly severe when associated to informal waste recycling practices. These uncontrolled processes can determine different contamination scenarios, depending on both the processed kinds of WEEE and the treatment operating conditions.

As long as WEEE management relies on rudimentary, unregulated practices despite the increasing amount to be handled, both workers and population living in the surroundings of the informal working sites will be exposed to potentially hazardous concentration of pollutants in air, soil and water.

Cesaro et al. (2018) has recently proposed a strategy to identify the relative potential harm of different kinds of WEEE by their content in metals, selected as target contaminants. Although the proposed methodology indicated a prioritization criteria for WEEE management, the quantification of the risks associated to the possible contamination scenarios represents one of the main challenges in this area (Grant et al., 2013; Rim et al., 2013).

The comprehensive characterization of both inorganic and organic contaminants that can be generated during WEEE informal treatment as well as the identification of human exposure to complex contaminant mixtures still hinder the assessment of the risk for human health, which could address the definition of either guidelines or best practices.

Dealing with these aspects is a demanding task, especially when considering WEEE characteristics, in terms of material composition. The evolution in technology includes indeed the use of different and innovative substances for EEE production, so that the characterization of what can be released or generated when the end-of-life EEE undergoes a specific informal treatment practice can vary with the device as well as over time.

Risk based procedures could be also of support for the definition of a specific regulatory framework: a direct transfer of the solutions implemented in developed countries does not seem to be applicable indeed, due to the specific socio-economic conditions of different areas.

In order to take into account local socio-economic dynamics, a legally established integration between formal and informal system has been proposed as a valuable alternative to strict and punitive laws (Ardi and Leisten, 2016). According to this approach, the informal sector should handle both collection and manual dismantling, to separate valuable WEEE components; the formal sector should be in charge of both the metal refining process and the disposal of residues.

This kind of measure could reduce the volume of WEEE generated on site and entering the informal sector. However, such upstream strategy should go hand in hand with policies acting on the illegally imported WEEE.

In this view, the involvement of developed countries is fundamental: the strengthening of WEEE regulations on separate collection and recycling targets, the clear distinction between second-hand appliances and waste as well as the export banning of the latter are possible actions to reduce mislead streams to developing countries, decreasing the share of waste treated within informal systems.

More efforts are needed to address these issues, and more field studies should be carried out to either support or validate the research work.

\section{Conclusive remarks and future perspectives}

WEEE management has raised as an attractive as well as challenging issue in the last few years.

The presence of valuable metals and critical elements acts as a driver for its recycling, whereas the heterogeneous composition and the content of hazardous substances hinder the sustainability of material recovery. Such conditions are even more complex if WEEE handling is intended to comply with the circular economy principles.

In this context, the role of interdisciplinary research seems fundamental to address the current, pressing issues dealing with WEEE characterization, collection, treatment as well as facing the global WEEE trades and the related impacts, both in terms of human health and environmental protection.

WEEE production minimization and the identification of strategies pursuing the effective extraction of materials to 
be brought back into production processes requires the comprehensive understanding of the material composition as well as the in-depth study of innovative and materialselective recycling treatments. A trans-national approach is also worth pursuing, in order to overcome the limits set by locally established conditions, so as to support WEEE management in a circular economy approach while protecting both human and environmental health on global scale.

\section{Acknowledgments}

This article is based on work from COST Action ES 1407 ReCreewEuropean network for innovative recovery strategies of rare earth and other critical metals from electrical and electronic waste, supported by COST (European Cooperation in Science and Technology - www.cost.eu).

\section{References}

Ardi R. and Leisten R. (2016), Assessing the role of informal sector in WEEE management systems: A System Dynamics approach, Waste Management, 57, 3-16.

Baldé C.P., Wang F., Kuehr R. and Huisman J. (2015), The Global Ewaste Monitor - 2014, United Nations University, IAS SCYCLE, Bonn, Germany.

Bigum M., Brogaard L. and Christensen T.H. (2012), Metal recovery from high-grade WEEE: A life cycle assessment, Journal of Hazardous Materials, 207-208, 8-14.

Buchert M., Manhart A., Bleher D. and Pingel D. (2012), Recycling Critical Raw Materials from Waste Electronic Equipment, Freibg. Öko-Inst. EV.

Cesaro A., Marra A., Belgiorno V., Siciliano A. and Guida M. (2017a), Chemical characterization and toxicity assessment for the sustainable management of end of life cathode ray tubes, Journal of Material Cycles and Waste Management, https://doi.org/10.1007/s10163-017-0685-2.

Cesaro A., Marra A., Belgiorno V. and Guida M. (2017b), Effectiveness of WEEE mechanical treatment: separation yields and recovered material toxicity, Journal of Cleaner Production, 142, 2656-2662.

Cesaro A., Belgiorno V., Vaccari M., Jandric A., Chund T.D., Dias M.I., Hursthouse A. and Salhofer S. (2018), A device-specific prioritization staregy based on the potential for harm to human health in informal WEEE recycling, Environmental Science and Pollution Research, 25, 693-692.

Chancerel P. (2010), Substance Flow Analysis of the Recycling of Small Waste Electrical and Electronic Equipment: an Assessment of the Recovery of Gold and Palladium, ClausthalZellerfeld, Papierflieger.

Chancerel P. and Rotter S. (2009), Recycling-oriented characterization of small waste electrical and electronic equipment, Waste Management, 29, 2336-2352.

Corsini F., Rizzi F. and Frey M. (2017), Extended producer responsibility: The impact of organizational dimensions on WEEE collection from households, Waste Management, 59, 23-29.

Cossu R. and Williams I.D. (2015), Urban mining: Concepts, terminology, challenges, Waste Management, 45, 1-3.

Cucchiella F., D’Adamo I., Lenny Koh S.C. and Rosa P. (2015), Recycling of WEEEs: An economic assessment of present and future e-waste streams, Renewable and Sustainable Energy Reviews, 51, 263-272.

Cui J. and Forssberg E. (2003), Mechanical recycling of waste electric and electronic equipment: a review, Journal of Hazardous Materials, 99, 243-263.

Cui J. and Zhang L. (2008), Metallurgical recovery of metals from electronic waste: A review, Journal of Hazardous Materials, 158, 228-256.

Ghosh B., Ghosh M.K., Parhi P., Mukherjee P.S. and Mishra B.K. (2015), Waste Printed Circuit Boards recycling: an extensive assessment of current status, Journal of Cleaner Production, 94, 5-19.

Global Metal Flows Working Group of the International Resource Panel of UNEP (2013), Metal Recycling: Opportunities, Limits, Infrastructure, Report 2b, Nairobi, Kenya.

Grant K., Goldizen F.C., Sly P.D. Brune M.-N., Neira M., van den Berg M. and Norman R.E. (2013), Health consequences of exposure to e-waste: a systematic review, Lancet Global Health, 1, e350-e361.

Guna V.K., Murugesan G., Basavarajaiah B.H., Ilangovan M., Olivera S., Krishna V. and Reddy N. (2016), Plant-based completely biodegradable printed circuit boards, IEEE Transactions Electronic Devices, 63, 4893-4898.

Hagelüken C. (2006), Recycling of electronic scrap at Umicore precious metals refining, Acta Metallurgica Slovaca, 12, 111-120.

Işılldar A., van de Vossenberg J., Rene E.R., van Hullebusch E.D. and Lens P.N.L. (2017), Biorecovery of metals from electronic waste. In: Heavy Metal Remediation. Environmental Chemistry for a Sustainable World, Rene E., Sahinkaya E., Lewis A. and Lens P. (Eds), Springer, Cham.

Lee J. and Pandey B.D. (2012), Bio-processing of solid wastes and secondary resources for metal extraction - A review, Waste Management, 32, 3-18.

Li J., Lopez N.B.N., Liu L., Zhao N., Yu K. and Zheng L. (2013), Regional or global WEEE recycling. Where to go? Waste Management, 33, 923-934.

Menad N. and van Houwelingen J.A. (2011), Identification and recovery of rare earth metals in electric and electronic scrap, In: Proceedıngs Sardını, Thirteenth International Waste Management and Landfill Symposium, CISA Publisher, Italy.

Morf L.S., Tremp J., Gloor R., Schuppisser F., Stengele M. and Taverna R. (2007), Metals, non-metals and PCB in electrical and electronic waste - Actual levels in Switzerland, Waste Management, 27, 1306-1316.

Oguchi M., Murakami S., Sakanakura H., Kida A. and Kameya T. (2011), A preliminary categorization of end-of-life electrical and electronic equipment as secondary metal resources, Waste Management, 31, 2150-2160.

Oguchi M., Sakanakura H., Terazono A. and Takigami H. (2012), Fate of metals contained in waste electrical and electronic equipment in a municipal waste treatment process, Waste Management, 32, 96-103.

Oguchi M., Sakanakura H. and Terazono A. (2013), Toxic metals in WEEE: Characterization and substance flow analysis in waste treatment processes, Science of the Total Environment, 463464, 1124-1132.

Ongondo F.O., Williams I.D. and Cherrett T.J. (2011), How are WEEE doing? A global review of the management of electrical and electronic wastes, Waste Management, 31, 714-730. 
Rim K.T., Koo K.H. and Park J.S. (2013), Toxicological Evaluations of Rare Earths and Their Health Impacts to Workers: A Literature Review, Safety and Health at Work, 4, 12-26.

Rubin R.S., de Castro M.A.S., Brandão D., Schalch V. and Ometto A.R. (2014), Utilization of Life Cycle Assessment methodology to compare two strategies for recovery of copper from printed circuit board scarps, Journal of Cleaner Production, 64, 297-305.

Schluep M. (2014), Chapter 29 - Informal waste recycling in developing countries, In: Handbook of Recycling, Elsevier, Boston.

Sepúlveda A., Schluep M., Renaud F.G., Streicher M., Kuehr R., Hagelüken C. and Gerecke A.C. (2010), A review of the environmental fate and effects of hazardous substances released from electrical and electronic equipments during recycling: Examples from China and India, Environmental Impact Assessement Review, 30, 28-41.

Tansel B. (2017), From electronic consumer products to e-wastes: Global outlook, waste quantities, recycling challenges, Environment International, 98, 35-45.

Tanskanen P. (2013), Management and recycling of electronic waste, Acta Materialia, 61, 1001-1011.

Tesfaye F., Lindberg D., Hamuyuni J., Taskinen P. and Hupa L. (2017), Improving urban mining practices for optimal recovery of resources from e-waste, Minerals Engineering, 111, 209-221.

Tsydenova O. and Bengtsson M. (2011), Chemical hazards associated with treatment of waste electrical and electronic equipment, Waste Management, 31, 45-58.

Tuncuk A., Stazi V., Akcil A., Yazici E.Y. and Deveci H. (2012), Aqueous metal recovery techniques from e-scrap: Hydrometallurgy in recycling, Minerlas Engineering, 25, 2837.

Tunsu C., Petranikova M., Gergorić M., Ekberg C. and Retegan T. (2015), Reclaiming rare earth elements from end-of-life products: A review of the perspectives for urban mining using hydrometallurgical unit operations, Hydrometallurgy, 156, 239-258.

Widmer R., Oswald-Krapf H., Sinha-Khetriwal D., Schnellmann M. and Böni H. (2005), Global perspectives on e-waste, Environmetal Impact Assessment Reviews, 25, 436-458. 